\title{
A modification of the leaf-nets method for sampling benthic invertebrates in spring habitats
}

\author{
Antonio DI SABATINO, ${ }^{1 *}$ Giovanni CRISTIANO, ${ }^{1}$ Patrizia VIGNINI, ${ }^{1}$ Francesco Paolo MICCOLI, ${ }^{2}$ Bruno CICOLANI ${ }^{2}$ \\ ${ }^{1}$ Department of Life, Health and Environmental Sciences, University of L'Aquila, Via Vetoio, Coppito 1, 67100 L'Aquila; ${ }^{2}$ Department \\ of Civil-Architectural and Environmental Engineering, University of L'Aquila, Via G. Gronchi 18, 67100 L'Aquila, Italy \\ *Corresponding author: antonio.disabatino@univaq.it
}

\begin{abstract}
The full ecological potential of spring habitats remains relatively unexplored mostly because of the lack of standardized sampling procedures and difficulties to collect representative biological samples, especially in small-sized springs. Recent studies on sampling methodologies in spring habitats indicated that a modified Surber net with a reduced frame area, reliably describes the structure and composition of spring communities. This method, however, is very invasive and may severely impact the spring, especially when a large number of samples is required. The paper presents a new quantitative method (leaf-nets) for sampling crenic invertebrates which combines a rather high efficiency with negligible impacts on spring habitat structure and biota. The effectiveness of the new methodology was tested in a medium-size rheocrene spring in Central Apennine, where spring assemblages were sampled in parallel with a modified Surber net and with the new method. Taxa richness and density were higher in the Surber net, while no between-method differences were recorded for the number of insect taxa and Simpson diversity. Furthermore, the overall functional organization of Surber net and leaf-nets assemblages was very similar. The new method sampled only $25 \%$ of the individuals cumulatively collected, but $75 \%$ of the total richness, with a good representation of the structure and the functional organization of spring assemblages. In comparison with the Surber net, the negligible loss of information of the new method is highly compensated by its minor invasivity, lower impacts on spring microhabitats and invertebrate populations and by its higher versatility. Leaf-nets could also be used to assess leafdetritus breakdown in springs, thus allowing a better ecological characterization of these ecosystems.
\end{abstract}

Key words: Spring habitats; benthic invertebrates, biomonitoring; sampling methods; artificial substrates.

Received: June 2017. Accepted: July 2017.

\section{INTRODUCTION}

Sampling procedures in freshwater habitats remains a critical stage in the acquisition of data concerning structural and functional characteristics of aquatic biocoenoses (Friberg et al., 2011). The choice of appropriate sampling methods and the relative sampling effort are the main discriminating factors which determine the accuracy of the information (Humphries et al., 1998; Pinna et al., 2014). Studies comparing the efficiency of different sampling methods were performed for streams, shallow freshwater ponds and transitional waters (see for review Di Sabatino et al., 2014, 2015) but are nearly absent for spring habitats (but see Cantonati et al., 2008 and Rosati et al., 2016).

Springs are peculiar ecosystems; despite the often limited spatial extension and the constancy of abiotic parameters, they host a diverse and highly specialized fauna with many rare and endemic species (Botosaneanu, 1998), giving thus a substantial contribution to local and regional freshwater biodiversity (Williams and Danks, 1991; Di Sabatino et al., 2003; Cantonati et al., 2012; Carrol and Thorp, 2014). Studies on the ecology of springs and springbrooks (crenoecology) have substantially con- tributed to improve freshwater science knowledge, however, the full potential of crenic ecosystems remains still unexplored mostly because of the lack of standardized sampling procedures and difficulty to collect representative biological samples, especially in small-sized springs (Gerecke et al., 2011). The mosaic of habitats/microhabitats and the delicate equilibria which characterize vertical (groundwater/surfacewater), horizontal (terrestrial-semiaquatic-aquatic) and longitudinal (crenal-hypocrenalrhithral) spring ecotones are essential elements which mainly contribute to the high diversity of crenic assemblages (Cantonati et al., 2012; Glazier, 2014). Therefore, the natural characteristics of such delicate habitats should be preserved and not altered during faunistic and ecological surveys (Gerecke et al., 2007).

All available sampling methodologies for spring habitats were recently reviewed by Rosati et al. (2016). Active methods (Surber net, hand-kick net, moss and vegetation washing, Bou-Rouch pump, core sampler) seem more efficient compared to passive ones (light traps, emergence traps, drift nets, artificial substrates). A modified Surber net, with a reduced frame area, reliably describes the structure and composition of spring communities. How- 
ever, this method is very invasive and may severely impact the spring especially when a large number of replicates is required (Gerecke et al., 2011). Most of the remaining available methods are qualitative or only semiquantitative, and are thus not suitable for a comparative analysis of results.

The main objective of the paper is to propose a new quantitative method for sampling crenic invertebrates which combines a rather high efficiency with negligible impacts on spring habitat structure and biota. The new method is a modification of the leaf-nets (Di Sabatino et al., 2016), recently proposed as an alternative technique for sampling macroinvertebrates in non-wadeable streams. The sampling efficiency of the leaf-nets was compared to that of a small Surber net of equal sampling area in a rheocrene spring in Central Apennines (Italy).

\section{METHODS}

\section{Study area}

The Vera springs (L'Aquila, Abruzzo, Central Italy) are a complex of karst - limestone resurgences located inside a 30 ha of municipal protected site in the suburban area of the city of L'Aquila. "Capo Tempera" and "Capo Vera" represent the two main rheocrene spring sources, with an average annual discharge of $0.8 \mathrm{~m}^{3} \mathrm{~s}^{-1}$. We located our study area at "Capo Tempera" (coordinates $42^{\circ} 22^{\prime}$ $21.42^{\prime \prime} \mathrm{N}, 13^{\circ} 27^{\prime} 30.51$ ' E; altitude $664 \mathrm{~m}$ asl), where benthic invertebrates were sampled in a stretch starting from immediately below the spring source to the first 35 $\mathrm{m}$ of the originated springbrook. In this zone, the channel has a width of about $3 \mathrm{~m}$ and a mean depth of $0.2 \mathrm{~m}$, the substratum is mainly composed of gravel and pebbles and the water flows with an average current velocity of 0.44 $\mathrm{m} \mathrm{s}^{-1}$. The spring area is characterized by dense riparian tree cover of Populus nigra and Salix alba, while the aquatic vegetation in low current zones is dominated by Apium nodiflorum.

\section{Sampling procedure}

Spring assemblages were sampled in parallel with a small Surber net (Sn; $0.2 \mathrm{~m}$ x $0.3 \mathrm{~m}$; mesh size $=200 \mu \mathrm{m}$; area $=0.06 \mathrm{~m}^{2}$ ) and with the new leaf-nets method (LN). The modified LN (Di Sabatino et al., 2016) were assembled using two PVC nets $(0.10 \mathrm{~m} \times 0.15 \mathrm{~m}$; mesh size $=$ $0.01 \mathrm{~m}$ ) filled with a single layer of Populus nigra leaves (Fig. 1a). Two of these sampling units were anchored with plastic coated steel (Fig. 1b); assuming that both surfaces of LN are suitable for macroinvertebrate colonization, the total area of the sampling apparatus is thus equal to that of the Surber net. The leaf material was collected in the study area around the spring, immediately after abscission in the fall season, transported to the laboratory and left for a week in a dry and ventilated laboratory to complete the dehydration process. Finally, the leaves were dried in a thermostatic oven at $60^{\circ} \mathrm{C}$ for $72 \mathrm{~h}$.

The experiment started at the end of June 2015; 9 leafnets were placed along the $35-\mathrm{m}$ study area in order to cover all possible microhabitats. LN were fully submerged in water and anchored to the bottom with steel pegs and boulders to better mimic the natural accumulations of leaf material. After 30 days, LN were carefully retrieved, placed in plastic bags, labelled and transported to the laboratory. To avoid the loss of material, a hand net (mesh size $200 \mathrm{~mm}$ ) was used in the recovery phase. At each retrieval occasion 9 Surber samples were taken along the $35-\mathrm{m}$ study stretch. As we wanted to compare the overall structure and composition of benthic assemblages sampled with two different methods, the 9 samples (for each method) were pooled and treated as a single observation. The sampling procedure was repeated four times, from June to November 2015. In the laboratory, leaf-nets were cleaned to eliminate inorganic material and macroinvertebrates were separated from the remaining leaf detritus. All organisms from LN and Surber samples were preserved in $70 \%$ ethanol and successively identified to the lowest possible taxonomic level (family, genus or species) using a stereo microscope (Leica MZ9.5). Each taxon was assigned to Functional Feeding Groups (FFGs) following the classification of Merritt and Cummins (1996) and Tachet et al. (2000). At each sampling occasion, some hydraulic characteristics (channel depth and width, current velocity, discharge) and chemical-physical parameters (water temperature, $\mathrm{pH}$, conductivity, dissolved oxygen) were recorded by using a magnetic flow probe (FP 101) and a multiparametric probe (Hach-Lange HQ40D Multi).

\section{Data analysis}

The data were analyzed in the context of a balanced design with "method" as discriminant factor. Differences in the structure of assemblages were evaluated using Student's $t$-tests with taxa richness, number of insect taxa, invertebrate density (ind. $\mathrm{m}^{-2} \log (\mathrm{x}+1)$ transformed) and Simpson's diversity as dependent variables, after verification of assumptions of normality (Anderson-Darling test) and homogeneity of variances (Levene test). The PERmutational Multivariate ANalysis Of VAriance (PERMANOVA, Anderson, 2001) was used to assess differences in the composition of assemblages after fourth root transformation of original abundances and application of the Bray-Curtis similarity index.

The overall functional organization of assemblages sampled with both methods was compared by applying PERMANOVA on the Bray-Curtis resemblance matrix after fourth root transformation of FFG percentages. Differences in the relative abundance of single FFG were also 
assessed using Student- $t$ tests after arcsin square-root transformation of original percentages.

Statistical analyses were performed with Addinsoft ${ }^{\mathrm{TM}}$ software XLSTAT 2014.1.09 and PRIMER v6.1.16 and PERMANOVA + v1.0.6. The significance threshold for all tests was set at $\mathrm{P}=0.05$.

\section{RESULTS}

\section{Abiotic parameters}

The analysis of abiotic factors of the Vera spring indicates high temporal constancy of hydraulic and physicalchemical parameters throughout the whole period of investigation. The width of spring channel remained almost unchanged, while water depth (mean \pm sd $=$ $0.16 \pm 0.01 \mathrm{~m})$, current velocity $\left(0.44 \pm 0.07 \mathrm{~m} \mathrm{~s}^{-1}\right)$ and discharge $\left(0.22 \pm 0.04 \mathrm{~m}^{3} \mathrm{~s}^{-1}\right)$ were subjected to slight temporal variations. Dissolved oxygen $\left(10.77 \pm 0.55 \mathrm{mg} \mathrm{L}^{-1}\right)$, temperature $\left(8.6 \pm 0.7^{\circ} \mathrm{C}\right)$, conductivity $\left(289 \pm 5 \mu \mathrm{S} \mathrm{cm}^{-1}\right)$ and $\mathrm{pH}(7.46 \pm 0.25)$ did not vary considerably as well.

\section{Macroinvertebrate assemblages}

Overall, 34 taxa were sampled for a total of 31,750 individuals (Supplementary Tab. 1). The Surber net collected 31 out of the 34 taxa (23,805 individuals), while 25 taxa and 7945 individuals were sampled with the leaf-nets method. Twenty-two taxa are shared by both methods, while 9 were exclusive of Surber samples [Perla grandis (Rambur, 1841), Rhithrogena semicolorata (Curtis, 1884), Psychomidae, Rhyacophila foliacea Moretti, 1981, Limoniidae, Stratiomiydae, Lumbriculidae, Ostracoda and Nematoda] and 3 occurred only in the leaf-nets (Glossosomatidae, Simuliidae and pupae of Chironomidae).

On average, taxa richness (mean \pm sd: $\mathrm{Sn}=25 \pm 2$ taxa, $\mathrm{LN}=17 \pm 3$ taxa; $t$-test $=4.021, \mathrm{P}=0.007)$ and macroinverte-

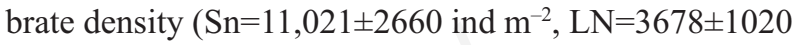
ind $\mathrm{m}^{-2} ; t$-test $\left.=5.906, \mathrm{P}=0.001\right)$ were significantly higher in Surber samples. However, the number of insect taxa ( $\mathrm{Sn}=16 \pm 3$ taxa, $\mathrm{LN}=12 \pm 3$ taxa; $t$-test $=2.131, \mathrm{P}=0.077$ ) and Simpson's diversity of assemblages ( $\mathrm{Sn}=0.66 \pm 0.03$, $\mathrm{LN}=0.56 \pm 0.09 ;$-test $=2.049, \mathrm{P}=0.086)$ did not show significant differences between Sn and LN samples (Fig. 2).
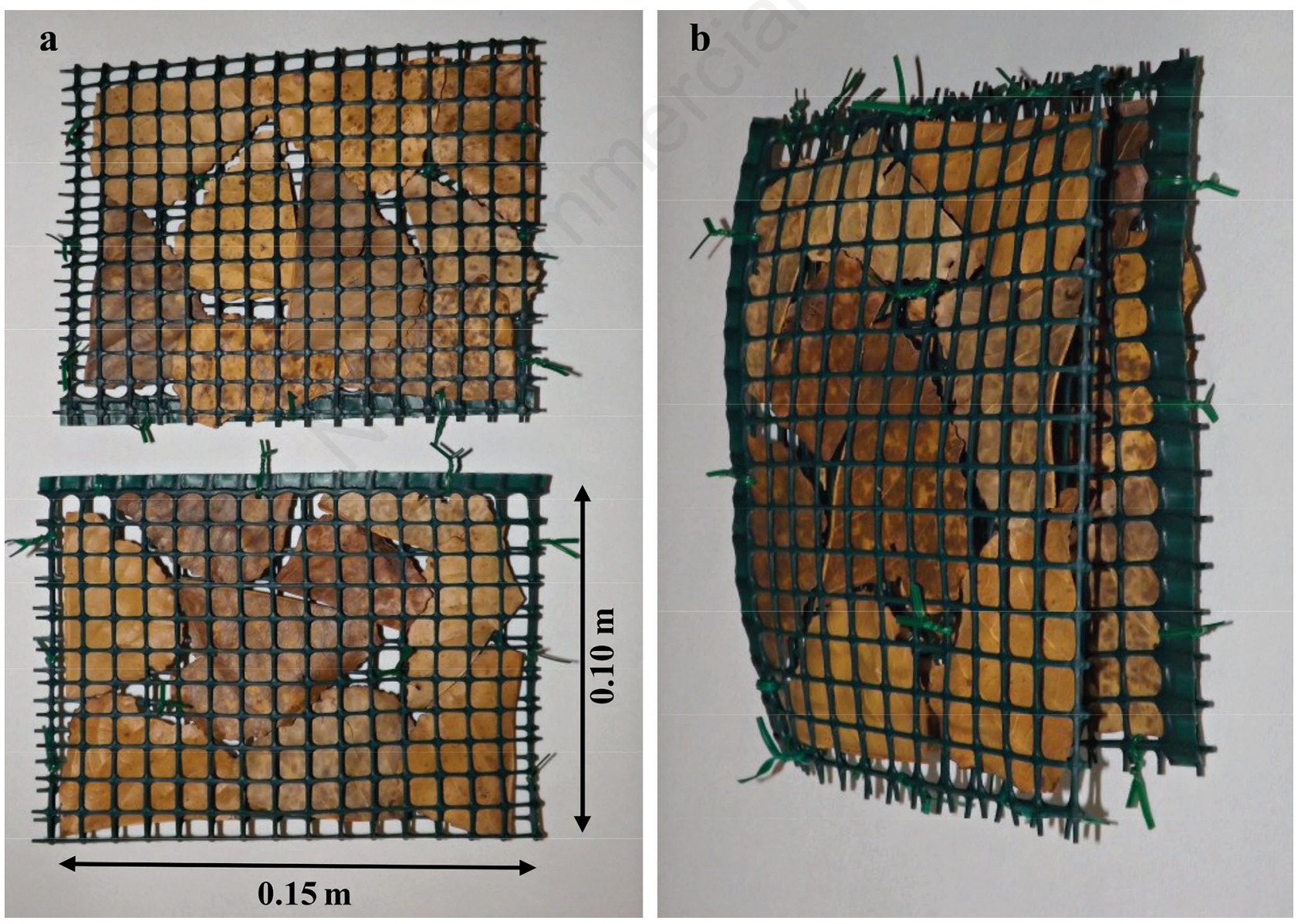

Fig. 1. Photos showing the new leaf-nets (LN) sampling device $\left(0.06 \mathrm{~m}^{2}\right)$ adapted to sample macroinvertebrates in spring habitats. See methods and Di Sabatino et al. (2016) for details on materials and construction procedures. 
Assemblages collected by the two methods were characterized by a different composition (PERMANOVA, pseudo- $F=14.712, \mathrm{P}($ perm $)=0.033)$. The amphipod Gammarus elvirae Iannilli and Ruffo, 2002 represented $44 \%$ of the individuals sampled with $\mathrm{Sn}$ and $30 \%$ of total individuals collected in LN. Conversely, the relative abundance of the crenobiont gastropod Belgrandia minuscula (Paulucci, 1881) was 57\% in LN and only $37 \%$ in Sn. Differences between the two methods are also due to higher percentages in Sn samples of Drusus aprutiensis Moretti, 1981 (6\%), Elmis aenea (Müller, 1806) (5\%) and Baetis rhodani (Pictet, 1843) (1\%); while Chironomidae (5\%), Schmidtea (=Dugesia) polychroa (Schmidt, 1861) (3\%) and Bythinella schmidtii (Küster, 1852) (2\%) were found in higher proportions in LN than in Sn samples.

Shredders and scrapers, almost equally divided, dominated (about $90 \%$ of the individuals collected) the assemblages of the Vera spring. The overall functional composition of assemblages sampled with the two methods did not differ significantly (PERMANOVA, pseudo-
$F=3.588, \mathrm{P}($ perm $)=0.059)$. However, a higher percentage of shredders was found on $\mathrm{Sn}$ samples $(\mathrm{Sn}=51 \%$, $\mathrm{LN}=31 \%$; $t$-test $=3.106, \mathrm{P}=0.021$ ). Between-method differences in mean percentages of scrapers, collector-gatherers and predators were not significant (all $t$-tests, $\mathrm{P}>0.45$; Fig. 3). Collector filterers were less than $1 \%$ in assemblages sampled with both methods.

\section{DISCUSSION}

Macroinvertebrate assemblages in the Vera spring are numerically dominated by non- insect taxa but, although with lower abundances, insects represent the more diversified faunistic group. This pattern is in agreement with results of similar studies in hard water springs of Europe, North America and New Zealand (Glazier, 1991; Goch and Glazier, 1991; Smith et al., 2003, Barquín and Death, 2006). Scrapers and shredders dominate the assemblages (more than $90 \%$ of the individuals collected) indicating an intermediate condition in the classification scheme of
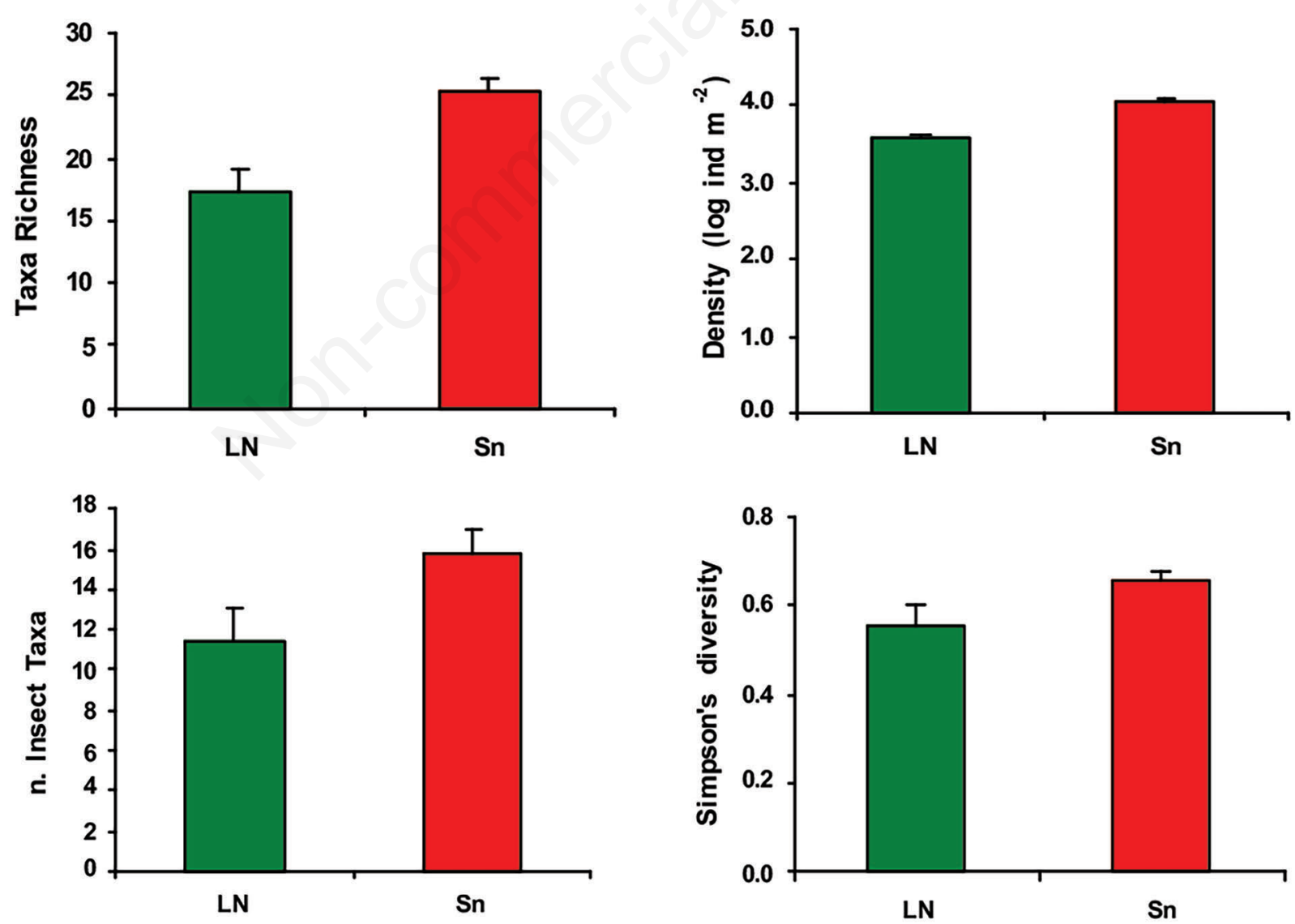

Fig. 2. Mean $(+1 \mathrm{SE})$ of taxa richness, density $[\log (\mathrm{x}+1)$ transformed], number of Insect taxa and Simpson's diversity of the Vera spring macroinvertebrate assemblages in leaf-nets (LN) and Surber samples (Sn). Significant differences were found only for taxa richness and density. 
spring functional organization recently proposed by von Fumetti and Nagel (2011).

Our study confirms the higher efficiency of active methods (Surber net) in collecting more individuals and more taxa in spring habitats (Rosati et al., 2016). However, no differences between Surber and LN samples were found for the number of insect taxa and Simpson's diversity. The composition of assemblages sampled by the two methods is also different, but the leaf-nets are able to capture the overall structure and composition of the Vera spring community. Differences are mainly due to the exclusive presence or higher abundance of highly mobile taxa in Surber net or also to the lower/higher propensity of some taxa to colonize leaf-nets (see below).

We should, however, emphasize that taxa richness and, marginally, densities of Vera spring leaf-nets assemblages are of the same order of magnitude, or also higher, in comparison to Surber samples of similar springs in Europe (Smith et al., 2003; Staudacher and Füreder, 2007; von Fumetti et al., 2007; Barquín and Death, 2009). Moreover, compared to other passive (semiquantitave) methods (Sangiorgio et al., 2010; Bottazzi et al., 2011; Rosati et al., 2016), leaf-nets seem to collect more information on the structure of spring communities.

The overall functional organization of the Vera spring in $\mathrm{Sn}$ and LN assemblages is very similar and non-significant between-method differences were found for the percentages of scrapers, predators and collectors-gatherers. However, contrary to what expected shredders are significantly more abundant in the benthos and show a lower propensity to colonize leaf-nets. This apparent contradiction could be explained by the high abundance of leaf detritus in the benthos. As observed by Tiegs et al. (2008), shredders tend to aggregate in leaf-bags only when benthic leaf resources are scarce or depleted. Conversely, the proportion of scrapers is higher in LN. Probably, the biofilm developing on the introduced leaves and the lower abundance of shredder competitors may favour scrapers colonization of leaf-nets.

\section{CONCLUSIONS}

The new method sampled only $25 \%$ of the individuals cumulatively collected but $75 \%$ of the total richness, with a good representation of the structure and the functional organization of the Vera spring assemblages. Compared to the Surber net, the loss of information of the new sampling method may be considered negligible and is highly compensated by a minor invasivity, a lower impact on spring microhabitas as well as on invertebrate populations and by a higher versatility. The area of the sampling device can be adapted in relation to the spring size and the leaf material can be chosen in relation to the type of canopy cover. Most importantly, the new sampling method also allows for a concomitant evaluation of the structural and functional (leaf litter breakdown) characteristics of spring ecosystems. We should also remark that, as other artificial substrates, the leaf-nets may act as a simple physical support, fully colonizable by aquatic microbiota and invertebrates (Di Sabatino et al., 2016). Therefore, they can be successfully utilised also in springs where the input of allochthonous leaf material is absent or of minor importance. However, further studies are needed to confirm the sampling efficiency of the leaf-nets in springs of different typologies.

Finally, we think that a less invasive sampling method may allow a more accurate ecological characterization of spring habitats, and could substantially contribute to the development of guidelines and protocols for the biomonitoring, conservation and management of such important and delicate freshwater ecotones.

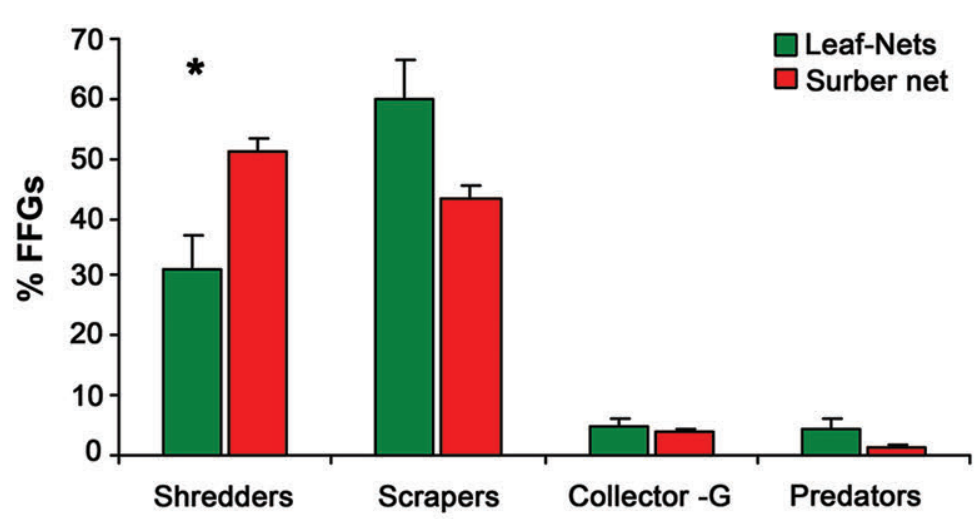

Fig. 3. Mean relative abundance ( $+1 \mathrm{SE}$ ) of Functional Feeding Groups (FFGs) in the assemblages of the Vera spring sampled with leaf-nets and Surber net. Collectors-G, collectors gatherers. 


\section{ACKNOWLEDGMENTS}

We thank Giulia Di Vito (L'Aquila) for field and lab work. Thanks are also due to Paola Lombardo (Limnoconsulting, Rome) for English language revision and useful comments on a first draft of the manuscript. Comments and suggestions of the editor and two anonymous reviewers substantially improved the text. The research was partially funded by the Regione Abruzzo (DPC024 - Servizio Gestione e Qualità delle Acque).

\section{REFERENCES}

Anderson MJ, 2001. A new method for non-parametric multivariate analysis of variance. Aust. Ecol. 26:32-46.

Barquín J, Death RG, 2006. Spatial patterns of macroinvertebrate diversity in New Zealand springbrooks and rithral streams. J. N. Am. Benthol. Soc. 25:768-786.

Barquín J, Death RG, 2009. Physico-chemical differences in karst springs of Cantabria, northern Spain: Do invertebrate communities correspond? Aquat. Ecol. 43:445-455.

Botosaneanu L, 1998. Studies in crenobiology. The biology of springs and springbrooks. Backhuys Publishers, Leiden: $261 \mathrm{pp}$.

Bottazzi E, Bruno MC, Pieri V, Di Sabatino A, Silveri L, Carolli M, Rossetti G, 2011. Spatial and seasonal distribution of invertebrates in Northern Apennine rheocrene springs. J. Limnol. 70:77-92.

Cantonati M, Bertuzzi E, Spitale D, 2008. The spring habitat: Biota and sampling methods. MUSE, Trento: $350 \mathrm{pp}$.

Cantonati M, Füreder L, Gerecke R, Jüttner I, Cox EJ, 2012. Crenic habitats, hotspots for freshwater biodiversity conservation: toward an understanding of their ecology. Freshw. Sci. 31:463-480.

Carroll TM, Thorp JH, 2014. Ecotonal shifts in diversity and functional traits in zoobenthic communities of karst springs. Hydrobiologia 738:1-20.

Di Sabatino A, Cicolani B, Gerecke R, 2003. Biodiversity and distribution of water mites (Acari, Hydrachnidia) in spring habitats. Freshwater Biol. 48:2163-2173.

Di Sabatino A, Cristiano G, Pinna M, Lombardo P, Miccoli FP, Marini G, Vignini P, Cicolani, B, 2014. Structure, functional organization and biological traits of macroinvertebrate assemblages from leaf-bags and benthic samples in a thirdorder stream of Central Apennines (Italy). Ecol. Indic. 46:84-91.

Di Sabatino A, Cristiano G, Pinna M, Lombardo P, Miccoli FP, Marini G, Vignini P, Cicolani B, 2015. Corrigendum to: Structure, functional organization and biological traits of macroinvertebrate assemblages from leaf-bags and benthic samples in a third-order stream of Central Apennines (Italy) [Ecol. Indic. 2014;46:84-91]. Ecol. Indic. 49:260.

Di Sabatino A, Cristiano G, Di Sanza D, Lombardo P, Giansante C, Caprioli R, Vignini P, Miccoli FP, Cicolani B, 2016. LeafNets (LN): a new quantitative method for sampling macroinvertebrates in non-wadeable streams and rivers. Rivers Res. Appl. 32:1242-1251.

Friberg N, Bonada N, Bradley DC, Dunbar MJ, Edwards FK,
Grey J, Hayes RB, Hildrew AG, Lamouroux N, Trimmer M, Woodward G, 2011. Biomonitoring of human impacts in freshwater ecosystems: the good, the bad and the ugly, p. 168. In: G. Woodward (ed.), Ecosystems in a human-modified landscape. Elsevier, Amsterdam.

Gerecke R, Cantonati M, Spitale D, Stur E, Wiedenbrug S, 2011. The challenges of long-term ecological research in springs in the northern and southern Alps: indicator groups, habitat diversity, and medium-term change. J. Limnol. 70:168-187.

Gerecke R, Maiolini B, Cantonati M, 2007. Collecting meioand macrozoobenthos in springs, p. 265-274. In: M. Cantonati, E. Bertuzzi, and D. Spitale (eds.), The spring habitat: biota and sampling methods. MUSE, Trento.

Glazier DS, 1991. The fauna of North American temperate cold springs: patterns and hypotheses. Freshwater Biol. 26:527-542.

Glazier DS, 2014. Springs. In: E.A. Elias (ed.), Reference module in earth systems and environmental sciences. Elsevier, Amsterdam.

Gooch JL, Glazier DS, 1991. Temporal and spatial patterns in mid-Appalachian springs. Mem. Ent. Soc. Can. 155:29-49.

Humphries P, Growns JE, Serafini LG, Hawking JH, Chick AJ, Lake PS, 1998. Macroinvertebrate sampling methods for lowland Australian rivers. Hydrobiologia 364:209-218.

Merritt RW, Cummins KW, 1996. An introduction to the aquatic insects of North America. Kendall Hunt Publishing Co, Debuque.

Pinna M, Marini G, Mancinelli G, Basset A, 2014. Influence of sampling effort on ecological descriptors and indicators in perturbed and unperturbed conditions: A study case using benthic macroinvertebrates in Mediterranean transitional waters. Ecol. Indic. 37:27-39.

Rosati M, Cantonati M, Fenoglio S, Segadelli S, Levati G, Rossetti G, 2016. Is there an ideal protocol for sampling macroinvertebrates in springs? J. Freshwater Ecol. 31:199209.

Sangiorgio F, Glazier DS, Mancinelli G, Basset A, 2010. How can habitat size influence leaf litter decomposition in five midAppalachian springs (USA)? The importance of the structure of the detritivorous guild. Hydrobiologia 654:227-236.

Smith H, Wood PJ, Gunn J, 2003. The influence of habitat structure and flow permanence on invertebrate communities in karst spring systems. Hydrobiologia 510:53-66.

Staudacher K, Füreder L, 2007. Habitat complexity and invertebrates in selected Alpine springs (Schütt, Carinthia, Austria). Internat. Rev. Hydrobiol. 92:465-479.

Tachet H, Bournaud M, Richoux P, Usseglio-Polatera P, 2000. [Invertébrés d'eau douce: Systématique, biologie, écologie].[Book in French]. CNRS Editions, Paris: 608 pp.

Tiegs SD, Peter FD, Robinson CT, Uehlinger U, Gessner MO, 2008. Leaf decomposition and invertebrate colonization responses to manipulated litter quantity in streams. J. N. Am. Benthol. Soc. 27:321-331.

von Fumetti S, Nagel P, 2011. A first approach to a faunistic crenon typology based on functional feeding groups. J. Limnol. 70: 47-154.

von Fumetti S, Nagel P, Baltes B, 2007. Where a springhead becomes a springbrook - a regional zonation of springs. Fund. Appl. Limnol. 169:37-48.

Williams DD, Danks HV, 1991. Arthropods of springs, with particular reference to Canada. Mem. Ent. Soc. Can. 155:1-135. 